\title{
СОЦИАЛЬНОЕ ИНВЕСТИРОВАНИЕ КАК ФАКТОР РАЗВИТИЯ КОНКУРЕНТНЫХ ПРЕИМУЩЕСТВ БИЗНЕСА В УСЛОВИЯХ ЭКЗОГЕННОЙ НЕСТАБИЛЬНОСТИ
}

\author{
(c) 2019 Волнухин Константин Васильевич \\ аспирант \\ институт бизнеса и делового администрирования \\ Российская академия народного хозяйства и государственной службы \\ при Президенте Российской Федерации (РАНХиГС), Россия, Москва \\ E-mail: lisenok022@gmail.com
}

В статье подчеркнута значимость управления конкурентными преимуществами в современных социально-экономических системах. Выделена роль социальной ответственности в контексте наращивания конкурентоспособности бизнес-структуры. Изучены принципы социального инвестирования; проанализирована классификация социальных инвестиций.

Ключевые слова: корпоративная социальная ответственность, социальное инвестирование, конкурентные преимущества, конкуренция, конкурентоспособность.

Отказ от экспортно-сырьевой модели экономики и превращение Российской Федерации в ведущую мировую державу XXI века должны быть связаны с формированием нового механизма взаимодействия, основанного на сбалансированности и синергетичном развитии свободы бизнеса, социальной справедливости и национальной конкурентоспособности. Данные предпосылки детерминируют необходимость отечественного бизнеса осуществлять внедрение концепции корпоративной социальной ответственности и реализовывать активную политику в сфере социальных инвестиций, что подчеркивает актуальность темы исследования.

Целью статьи является анализ основных теоретико-методологических и практических аспектов социального инвестирования как инструмента формирования и развития конкурентных преимуществ бизнес-структур. Методология исследования представлена методами сравнения, классификации, синтеза. Специфика социального инвестирования как практического выражения корпоративной социальной ответственности является востребованным предметом научных исследований как за рубежом, так и в России. Проблемы и перспективы социального инвестирования как фактора развития конкурентных преимуществ организации и достижения позитивной стабильности на макроуровне анализируют в своих научных трудах такие современные российские ученые, как Анкудинов А.Б., Борисов Д.М., Бубнов Г.Г., Семенов А.В., Хача- турян К.С., Водяненко О.И., Вотченко Е.С., Денисов А.Э., Зарецкий А.Д., Иванова Т.Е., Ильина Г.Н., Кабир Л.С., Минина Т.И., Скалкин В.В., Сорокина Е.А., Третьяков О.В., Федотова М.А., Данилова О.В., Фомин М.В., Щербаченко П.С. и др. Несмотря на значительное число исследований, посвященных данному вопросу, категория социального инвестирования как нового направления формирования и укрепления конкурентных преимуществ бизнеса все же не получила универсальной трактовки: единообразной позиции по вопросам методологии построения, анализа, оценки и управления социальным инвестированием еще не выработано, что ведет к многозначности данной дефиниции в целом. При этом существующие научные позиции можно воспринимать и как антагонистичные, и как взаимодополняющие и не вступающие в противоречие, но лишь подчеркивающие тот или иной аспект проблемы, наиболее значимый с позиции конкретного исследователя.

Рассматривая сущностное определение конкурентного преимущества как условия достижения конкурентоспособности предприятия, укажем на основополагающее определение конкурентного преимущества как набора интегрированных отличительных характеристик, обеспечивающего превосходство бизнес-системы над конкурентами. Конкурентное преимущество проявляется, если предприятию удается выполнить наращивать ценность продукта для потребителя и повышать добавленную стоимость с 
более низкими совокупными издержками, чем у ее конкурентов. Важными характеристиками конкурентного преимущества можно признать относительность (т.е. оценка относительно отраслевого бенчмарка или группы основных конкурентов) и конкретность (определенность, дискретность, проявляемость на определенных рынках в течение определенного временного промежутка) [2]. Сформированные конкурентные преимущества организации должны быть достаточны для реализации конкурентной стратегии развития организации в целях получения желаемых результатов деятельности и соответственно конкурентоспособности организации в целом, как непосредственного фактора успеха ее деятельности.

Поскольку для обеспечения нормального функционирования и конкурентоустойчивого развития бизнес-структуры во всех ее принципиальных решениях должно быть достигнуто согласование интересов как внутриорганизационных субъектов, так и субъектов объективной социальной среды (без которой существование корпорации не является возможным), все более актуальной становится концепция корпоративной социальной ответственности и социального инвестирования. Корпоративная социальная ответственность (КСО) является концепцией, которая отражает добровольное решение компаний инвестировать ресурсы в улучшение социальной среды и реализацию экологических программ. Различные научные школы предлагают многообразие дефиниций КСО, однако системообразующим можно считать определение, изложенное в Международном стандарте ISO 26000 «Руководство по социальной ответственности» (Guidance on social responsibility). Стандарт ISO отражает 7 ключевых тем социальной ответственности (вовлеченность и развитие сообщества; права человека; охрана окружающей среды; организационное управление; практика труда; проблемы потребителей; практика справедливого управления) и фиксирует центральные результаты использования данного подхода: формирование конкурентных преимуществ за счет многоуровневого укрепления репутации, привлечение и наращивание лояльности сотрудников, клиентов и контактных аудиторий.

Социальное инвестирование представляет собой деятельность компаний, осуществляемую в рамках концепции КСО и направленную на вложение корпоративных ресурсов в обще- ственную жизнь, в общественные отношения, в совместную деятельность индивидов с целью получения социального эффекта [4]. Результатом корпоративного социального инвестирования является производство продукта или оказание услуги, обладающей социальными характеристиками - то есть значимыми и полезными для социума в целом, а не только для его отдельных частей. Основным принципом, регулирующим данный механизм воздействия сектора бизнеса на социальную среду является осуществление деятельности как с целью удовлетворения потребностей населения, так и с целью достижения определенных положительных эффектов непосредственно для компании-инвестора. Другими важными принципами осуществления корпоративных социальных инвестиций являются принцип про-активности; ориентированности на развитие инфраструктуры; содействия макроэкономическому и социальному росту, инновационной направленности экономики; стратегической ориентированности; превалирования инвестиционной сущности над благотворительной в социальной корпоративной работе (табл. 1).

Анализируя рассмотренные принципы, следует еще раз подчеркнуть двойственную природу социальных инвестиций. Для любого бизнеса важны социальные связи, которые в определенной мере вызывают необходимость им соответствовать и реализовывать новые цели. В зависимости от зрелости рыночных отношений, от общественной структуры и взаимодействия социальная ориентация бизнес проходит через благотворительность, меценатство, шефство, спонсорство, разовые и системные связи с общественными структурами. Социальная ориентация и нацеленность бизнеса идут в целостном единстве с капитализацией бизнеса, усиливая положение фирмы через социализацию обязанностей предпринимателя перед обществом [6]. Социальная сущность государства и бизнеса связана с удовлетворением социальных потребностей и достижением эффекта от социальных вложений. В этой связи следует подчеркнуть важность социальной защиты, справедливости, поддержки нетрудоспособных, нивелирования социальных различий, устранение конфликтов, доминирование культурно-нравственных и альтруистических принципов.

Не снижая важности коммерческих целей бизнеса по повышению прибыли, рейтинга, 
Таблица 1. Принципы корпоративного социального инвестирования

\begin{tabular}{|c|c|}
\hline Принцип & Характеристика \\
\hline Принцип про-активности & $\begin{array}{l}\text { Корпорация не должна дожидаться, чтобы ее попросили/принудили к } \\
\text { инвестированию в социальные проекты - менеджменту следует проявлять } \\
\text { инициативу, основанную на тщательном анализе возможных направлений } \\
\text { социального инвестирования. }\end{array}$ \\
\hline $\begin{array}{l}\text { Ориентированность на } \\
\text { развитие инфраструктуры }\end{array}$ & $\begin{array}{l}\text { Компания должна выбирать проекты для инвестиций таким образом, чтобы } \\
\text { они максимально оказывали помощь в ремонте и строительстве оборудова- } \\
\text { ния для социального развития. Современное состояние России таково, что } \\
\text { необходимым является значительное увеличение инвестиций во все секторы } \\
\text { инфраструктуры - от коммунального хозяйства до современных транспорт- } \\
\text { ных систем и энергетики. }\end{array}$ \\
\hline $\begin{array}{l}\text { Содействие экономическому } \\
\text { и социальному росту, инно- } \\
\text { вационной направленности } \\
\text { экономики }\end{array}$ & $\begin{array}{l}\text { Своими инвестициями корпорациям необходимо создавать условия для } \\
\text { дальнейшего повышения уровня жизни и поддержания макроэкономиче- } \\
\text { ской стабильности. }\end{array}$ \\
\hline $\begin{array}{l}\text { Стратегическая ориентиро- } \\
\text { ванность }\end{array}$ & $\begin{array}{l}\text { Корпорациям следует ориентироваться на оказание постоянной или долго- } \\
\text { срочной поддержки и помощи в реализации социальных проектов, связан- } \\
\text { ных с объектом инвестирования. }\end{array}$ \\
\hline $\begin{array}{l}\text { Превалирование инвестици- } \\
\text { онной сущности в социаль- } \\
\text { ной корпоративной работе } \\
\text { над благотворительной }\end{array}$ & $\begin{array}{l}\text { В условиях рынка социальные инвестиции повышают статус благотвори- } \\
\text { тельности, превращая это направление в одно из направлений развития и } \\
\text { оптимизации бизнеса, реализуемое всеми подразделениями предприятия. } \\
\text { Соц ацильное инвестирование превращается в базовую платформу, на осно- } \\
\text { ве которой формируется и развивается имидж, репутация и корпоративная } \\
\text { культура компании. } \\
\text { Интегрируя спонсорское и благотворительное влияния, социальные инве-- } \\
\text { стиции нацелены на повышение социальной эффективности бизнеса. Такая } \\
\text { социализация бизнес- процессов усиливает рыночные позиции компании, } \\
\text { обеспечивая новые рынки сбыта и каналы для продвижения товаров. При } \\
\text { этом развитие получает РR и рекламы, которые влияют на капитализацию } \\
\text { маркетинга, стоимость бренда и нематериальных активов. Социальная } \\
\text { направленность тесно связана с клиентоориентированностью маркетин- } \\
\text { га, с социально-этическим маркетингом и маркетингом взаимодействия, } \\
\text { что способствует развитию партнерских отношений с инфраструктурными } \\
\text { подразделениями и местными сообществами. На всем уровнях общества и } \\
\text { экономики, администрирования и конкурирования происходит повышение } \\
\text { качества отношений, осуществляется поддержка властями, создается каркас } \\
\text { для репутационного влияния и устойчивости в условиях рисков [6]. }\end{array}$ \\
\hline
\end{tabular}

имиджа и репутации в условиях современной общественной системы, становится важным сформировать экономическую отдачу от социальной деятельности, повысить лояльность и удовлетворенность клиентов и общества. Такая многоуровневая система формирования бизнесструктуры позволяет динамично наращивать стоимости бизнеса и сохранять права собственности. Мы обратили внимание на то, что успешный бизнес западных стран с середины XX века обновил миссию своего развития, выдвинув в качестве доминанты цель по созданию, реализации и совершенствованию человеческого капитала. Капитализация труда и профессионализма начинается с программы взаимодействия с обществом как заказчиком на образование и продолжается в русле вакансий и карьерного роста. Такой широкий подход по разному реализуется крупным и малым бизнесом. Но одно важно, что просто разовая поддержка, спонсорство и со- циальная защита некоторых групп людей и для общества и для бизнеса становится неэффективной и неперспективной. Бизнесу приходится решать социальные задачи под гнетом глобальной конкуренции, понимая, что социальные гарантии для персонала, социальная поддержка для общества могут сочетаться с рыночными механизмами, но имеют определенные границы.

В поведенческой теории фирмы, исследуя врожденный конфликт между целями индивидов и подгрупп внутри организации, можно утверждать, что цели организации оптимизируются и развиваются только при взаимодействии, компромиссе и взаимопонимании индивидов и подгрупп. Дж. Сайерт и Р. Марч выделили пять факторов, влияющих на производственную и ценовую стратегию компании. Это, прежде всего, факторы, которые позволяют решить задачи производственного обеспечения и развития, формирования запасов, выбора каналов сбыта, обо- 
снования рыночной доли и получения прибыли. Если общая цель компании связана с повышением конкурентоспособности, то решение перечисленных задач актуально для руководителей конкретных структурных подразделений организации. На уровне компании всегда идет выяснение отношений по поводу важности того или иного подразделения, что в свою очередь влияет на решение поставленных задач. Выбор компромиссного решения ведет к созданию из частных задач - задач интегрированных, общих, удовлетворяющих потребности всех или большинства субъектов организации.

Некоторые эксперты считают, что именно социальное инвестирование может стать общей, объединяющей целью, нивелирующей противоречия во внутренней и внешней среде. Социализация капитала через принадлежность к определенной группе, статуарность, через длительные субъективно-эмоциональные обязательства ведет к появлению новой «бизнес-модели», решающей более широкий перечень социальных задач. Комбинирование производственного, финансово-инвестиционного, интеллектуального и социального капитала, ведущего к воспроизводству социально-классовой, стратифицированной структуры общества через оптимизацию взаимоотношений, бизнес в условиях институциональной экономики повышает устойчивость, интенсифицируя свою роль в бизнес-пространстве. Развивая партнерские связи и взаимодействие на уровне предприятия и во внешней среде, бизнес в определенной мере перераспределяет свои права, укрепляя собственность за счет инвестирования в интеллектуальный человеческий капитал.

Повышению социальной эффективности способствуют количественные объемы социального инвестирования и качественные характеристики «зрелости и наполняемости» интеллектуального человеческого капитала. В отраслевой и институциональной структуре различия в производственной деятельности вызывают усиление социальную направленность в овладении определенными знаниями, компетенциями, мировоззренческими позициями, идеями и взглядами. На первое место выходит интеллектуальная собственность, оцениваемая по реальному весу и вкладу в развитие общества. В зависимости от комплиментарности и сочетаемости интересов социума, общественных групп и бизнеса, переформатируется первич- ная, разовая, спонтанная социальная поддержка и ответственность. Появляется новый вид социального ресурса, основанный на доверии и взаимодействии, формируются жизненные ценностные приоритеты, обеспечивающие синергетический эффект сотрудничества, развития, экономического роста.

Существует множество подходов к типологизации корпоративных социальных инвестиций, различающихся принципами, положенными в основу производимой классификации. Так определяющими критериями могут быть организационные формы, объекты, масштабы, цели инвестирования - т.е. специфические аспекты той или иной инвестиционной деятельности. В первую очередь все социальные инвестиции по типам инвестирования делятся на два основных вида: непосредственно социальные инвестиции (вложения в социальную сферу, человеческий капитал, инвестиции в социально-экономическую и социально-экологическую безопасность, формирование новых секторов экономики и создание социальных технологий) и опосредованные социальные инвестиции (хозяйственные инвестиции, несущие косвенный социальный эффект).

В зависимости от специфики выгоды, получаемой субъектом инвестирования, целесообразно выделить два класса социальных инвестиций: коммерческие (предусматривающие получение выгоды участниками в форме прямой платы за их участие в социальной деятельности) и некоммерческие. (нацеленные на обеспечение нерыночного производства социальных услуг и продуктов, главным результатом которых являются порождаемые ими социально значимые внешние эффекты и положительный имидж корпорации). По ожидаемому эффекту (результату) можно дифференцировать инвестиции с непосредственным (прямым) социальным эффектом; инвестиции с рассеянным социальным эффектом; инвестиции с косвенным социальным эффектом; инвестиции с опосредованным социальным эффектом, по масштабу реализации - инвестиции на на микроуровне, на мезоуровне, на макроуровне.

Дифференцируя социальное инвестирование с позиции направленности, можно выделить инвестирование внутреннее и внешнее в контексте преимущественной ориентированности на окружающую среду и внешних стейкхолдеров или внутриорганизационное про- 
странство. Приоритетными среди внутренних социальных инвестиций являются вложения, связанные с развитием человеческого капитала персонала компании - охраной здоровья и мероприятиями по подготовке и повышению квалификации кадров [5]. Наиболее распространенные направления внешних социальных инвестиций - вложения в природоохранную деятельность и ресурсосбережение, поддержку местного сообщества, повышение культуры во взаимоотношениях с потребителями и деловыми партнерами.

Еще одним направлением классификации может быть выделением масштабов реализации корпоративных инвестиционных проектов. Согласно данному критерию можно выделить инвестиции, осуществляемые:

- на микроуровне - малые проекты (локальные, точечные);

- на мезоуровне - средние (местные проекты, региональные и отраслевые программы)

- на макроуровне - крупные (федерального масштаба), глобальные (общемировые, межгосударственные).

Рассматривая современное состояния сферы корпоративного социального инвестирования в России, укажем, что, учитывая сырьевую ориентацию экономики нашей страны, именно нефтегазовые компании лидируют среди российского бизнеса как по объему социальных инвестиций, так и по масштабу мероприятий, входящих в сферу КСО. По разным оценкам, на эти цели нефтегазовые компании направляют от 1 до 4 процентов годовой чистой прибыли. Основными направлениями социального инвестирования бизнес-структур нефтегазового сектора являются развитие региональной инфраструктуры (строительство новых школ, спортивных и культурных объектов, лечебных учреждений), поддержка собственных сотрудников, улучшение условий их труда и качества жизни в целом, обеспечение экологической безопасности. Например, «Лукойл» в 2017 году потратил на внешнюю социальную поддержку около 9 миллиардов рублей (2,14\% от чистой готовой прибыли); на программу промышленной безопасности и охраны труда - 12,3 миллиарда рублей (2,93\%). НК «Роснефть» уделяет особое внимание возмещению нанесенного ущерба водным биоресурсам в регионах работ: в 2017 году было выпущено около 12 миллионов разновозрастной молоди таких пород, как пелядь, семга, сибирский осетр, стер- лядь, сиг и хариус. Другая национальная корпорация - «Газпром» - ежегодно поддерживает множество общественных проектов, оказывая помощь в развитии культуры, науки, образования, пропаганде здорового образа жизни. При этом по оценкам самой корпорации, главным социальным проектом 2017 года являлась газификация регионов страны, позволившая привести сетевой газ более чем в 200 населенных пунктов. В рамках еще одного масштабного социального проекта - «Газпром - детям» - в 2017 году были построены 165 спортивных объектов [15].

Содействие развитию процессов социального инвестирования, призванного гармонизировать взаимодействие общества, государства и бизнеса, в России осуществляет Ассоциация менеджеров - независимая общественная профессиональная организация национального масштаба. Согласно оценкам экспертов Ассоциации менеджеров, сфера КСО в нашей стране продолжает развиваться, и для лидеров бизнеса это не «мандариновая благотворительность» (единичные формальные поездки к нуждающимся с дорогими подарками), а серьезные стратегические инвестиции с эффектами разных уровней. Дополнительно можно отметить географическую специфику социального инвестирования бизнеса в России: в стране функционирует значительное количество градообразующих предприятий, которые зачастую находятся в труднодоступных районах с суровым климатом. Проекты по созданию площадок для деятельности некоммерческих организаций, организации разнообразных фестивалей, реализации программ цифровизации (в рамках которых проводится качественный высокоскоростной Интернет) позволяют бизнесу повышать привлекательность и комфортность жизни в столь непростых и ранее неразвитых локациях, что является инвестицией в привлечение и удержание высококвалифицированных молодых специалистов [15].

Итак, обеспечение конкурентоустойчивости бизнес-структры в условиях социокультурных трансформаций, макроэкономической нестабильности и обострения геополитических противоречий требует сонаправленности интересов как внутриорганизационных стейкхолдеров, так и субъектов объективной социальной среды, без которой существование любой предпринимательской структур не представляется возможным. В качестве инструмента подобного согласования интересов может выступать концепция 
социальной ответственности и социального инвестирования, позволяющая бизнесу выстраивать взаимовыгодные отношения с представителями как внешней, так и с внутренней среды: конкуренция между субъектами и объектами рынка вызывает к жизни новые формы взаимодействия между элементами, чтобы противостоять негативным факторам, реагировать на вызовы рынка и способствовать балансу отношений между бизнесом и обществом. Основным принципом, регулирующим данный механизм воздействия корпоративного сектора на социальную среду является осуществление деятельности как с целью удовлетворения потребностей населения, так и с целью достижения определенных положительных эффектов (по сути - укрепления конкурентных позиций) непосредственно для компании-инвестора. В зависимости от многогранного и емкого понимания конкурентоспособности выстраивается и синхронизируется пирамида связей, отношений и стратегий по клиентоориентированности и удовлетворению рыночных потребителей. Способность конкурирования по сути может быть связана с полным соответствием требованиям рынка, когда предлагаемая продукция не хуже рыночных аналогов конкурентов или превосходит их по качеству, ассортименту в конкретных сегментах рынка. Конкретность может проявляться по инновационному товарному и услуговому потенциалу, по уровню восприятия достижений предприятия общественными структурами. К экзогенных факторам мы относим макрофакторы международной среды, макрофакторы на национальном промышленном, финансово-кредитном, антимонопольном, научно-техническом и социаль- ном уровне; мезофакторы, действующие в отрасли и регионе. Социальное инвестирование зависит от экономической, социальной политики, от научно-технического, инновационно- инвестиционного потенциала отрасли и региона. В этой связи уровень, стратификация и интенсивность социального инвестирования в основе своей зависит от активности бизнеса и направлена на получение прибыли от проектов в социальной сфере. Целью финансовой или другой ресурсной помощи общественным группам, долгосрочных партнерских программ является получение существенного социального эффекта, снижение социального напряжения в регионах и повышение социальной справедливости. Социально ответственный бизнес, достигая успехов в решении непосредственно коммерческих задач, вносит позитивный вклад в устойчивое экономическое и социальное развитие общества. Другими важными принципами осуществления корпоративных социальных инвестиций являются принцип про-активности (корпорация не должна дожидаться, чтобы ее попросили/принудили к инвестированию в социально активные проекты, корпорация должна проявлять инициативу, основанную на тщательном анализе возможным направлений социального инвестирования), ориентированности на развитие инфраструктуры в выборе объектов инвестирования, содействия макроэкономическому и социальному росту, инновационной направленности экономики; стратегической ориентированности и долгосрочной проработки плана инвестиционной деятельности; превалирования инвестиционной сущности над благотворительной в социальной корпоративной работе.

\section{Библиографический список}

1. Анкудинов А.Б., Борисов Д. М. Корпоративная социальная ответственность как фактор долгосрочного роста // Известия УрГЭУ. 2013. № 1 (45) С.109-114.

2. Бубнов Г.Г., Семенов А.В., Хачатурян К. С. Корпоративная социальная ответственность в условиях современной экономики // ТДР. 2011. № 6 С.106-107.

3. Водяненко О.И. Специфика корпоративных инвестиций в общественные блага // Вестник Саратовского государственного социально-экономического университета. 2012. № 3 (42) С.19-23.

4. Вотченко E.C. Корпоративное гражданство как международный стандарт: перспективы развития и векторы применения // Научный вестник Волгоградского филиала РАНХиГС. Серия: Политология и социология. 2017. № 4. С. 28-31.

5. Денисов А.Э. Формирование корпоративной социальной стратегии: основные принципы и инструменты // Проблемы современной экономики. 2013. № 2 (46) С.54-58.

6. Зарецкий А.Д., Иванова Т.Е. От предпринимательской благотворительности к корпоративным социальным инвестициям // Известия ВолгГТУ. 2014. № 17 (144) С.44-52. 
7. Ильина Г.Н. Социальная ответственность российского бизнеса: стратегии и инновации // Вестник МГИМО. 2014. № 1 (34) C.216-224.

8. Кабир Л. С. Социально ответственное инвестирование: тренд или временное явление? // Экономика. Налоги. Право. 2017. Т. 10. № 4. С. 35-41.

9. Минина Т.И., Скалкин В.В. Вызовы новой реальности в социальной ответственности бизнеса // Экономика. Налоги. Право. 2016. № 5 С.56-62.

10. Сорокина E. А. Корпоративная социальная ответственность предпринимательских структур // Социально-экономические явления и процессы. 2015. № 7 С.112-118.

11. Третьяков О.В. Социальное инвестирование как фактор устойчивости современной экономической системы // Научная мысль. 2016. № 1 (19). С. 67-72.

12. Федотова М.А., Данилова О.В. Социальное инвестирование как фактор развития конкурентных преимуществ российского бизнеса // Вестник Финансового университета. 2012. № 1 С.8-14.

13. Фомин М.В. Государство и бизнес: социокультурные аспекты взаимодействия // Среднерусский вестник общественных наук. 2018. Т. 13. № 1. С. 30-38.

14. Щербаченко П. С. Управление взаимодействием со стейкхолдерами в российских компаниях // Вестник Университета (Государственный университет управления). 2018. № 5. С. 155-161.

15. Носкова Е. Хариус вильнул хвостом. Компании поддерживают сотрудников и заботятся о природе // Российская газета. Спецвыпуск № 193 (7656). URL: https://cdnimg.rg.ru/pril/fascicle/3/68/74/36874-1535658978.pdf 